\title{
Breakdown characteristics of MOVPE grown Si-doped GaAs Schottky diodes
}

\author{
M.K. Hudait ${ }^{\text {a, b }}$, S.B. Krupanidhi ${ }^{\text {a,* }}$ \\ ${ }^{a}$ Materials Research Centre, Indian Institute of Science, Bangalore 560 012, India \\ ${ }^{\mathrm{b}}$ Central Research Laboratory, Bharat Electronics, Bangalore 560 013, India
}

Received 6 April 1999; received in revised form 26 June 1999

\begin{abstract}
The breakdown characteristics of $\mathrm{Au} / \mathrm{n}$-GaAs Schottky contacts on metal-organic vapor-phase epitaxy grown Sidoped $\mathrm{n}$-GaAs were measured in the doping range of $6 \times 10^{15}-1.5 \times 10^{18} \mathrm{~cm}^{-3}$. These results are compared with the experimentally measured breakdown voltages by several workers and also with the theoretical calculation predicted by Sze and Gibbons [Sze SM, Gibbons G. Appl. Phys. Lett. 1966;8:111]. Good agreement was observed between the measured data and the breakdown voltages by Sze and Gibbons in the high doping concentrations. The maximum depletion layer width is found to be in good agreement with the theoretical analysis by Sze and Gibbons. The breakdown voltage at higher doping concentration will be useful for the design and development of GaAs switching devices and the emitter-base region of bipolar transistors. (C) 1999 Elsevier Science Ltd. All rights reserved.
\end{abstract}

\section{Introduction}

The power rectifiers made of Schottky diodes with high-speed switching capabilities are required for a variety of power electronic applications, such as inverters, choppers, and switching power supplies [1-3]. The most useful applications of Schottky diodes are in lowvoltage, high-power as well as high-speed switching power supplies and control circuits [4-7]. The limitations of the improvement of Si Schottky diode parameters are imposed by the material properties, i.e. low carrier mobility and a relative narrow band gap. Compound semiconductor materials are known to result in surface Fermi-level pinning characteristics because of high density of surface states [8]. In ad-

\footnotetext{
* Corresponding author. Tel:. +91-80-331-1330; fax: +9180-334-1683.

E-mail addresses: mantu@mrc.iisc.ernet.in (M.K. Hudait), sbk@mrc.iisc.ernet.in (S.B. Krupanidhi)
}

dition, these materials provide improved electronic transport due to higher mobilities, wider band gap and higher peak electrical field strength at breakdown. The only material mature enough technologically and superior to $\mathrm{Si}$ is GaAs [1]. Epitaxial structures of GaAs with low-doped and thick enough epi-layers to obtain a reasonably high breakdown voltage are available, and different types of metal for the formation of Schottky barrier (SB) diodes deposition have been developed by several authors [1,3,9-13].

The avalanche breakdown voltage of GaAs Schottky diodes are available in the literature particularly at the doping level below $5 \times 10^{17} \mathrm{~cm}^{-3}$ by several authors [11-15]. However, very few results are available [16] on the breakdown voltage of GaAs diodes at doping concentration greater than $5 \times 10^{17} \mathrm{~cm}^{-3}$. The breakdown voltage at higher dopant concentration is very important to design the switching transistors and also the emitter-base region of bipolar transistors.

In this paper, we present the breakdown characteristics of Si-doped n-type GaAs Schottky diodes grown 
Table 1

Carrier concentration, thickness, breakdown voltage, maximum depletion layer width, and maximum electric field of the present investigated films

\begin{tabular}{|c|c|c|c|c|}
\hline \multirow[t]{2}{*}{$N_{\mathrm{D}}\left(\mathrm{cm}^{-3}\right)$} & \multicolumn{4}{|l|}{ This work } \\
\hline & Thickness of film $(\mu \mathrm{m})$ & $V_{\mathrm{BD}}(\mathrm{V})$ & $W_{\mathrm{m}}(\mu \mathrm{m})$ & $E_{\mathrm{m}}\left(\times 10^{5} \mathrm{~V} \mathrm{~cm}^{-1}\right)$ \\
\hline $6 \times 10^{15}$ & 4.5 & 28 & 2.56958 & 2.18 \\
\hline $2.5 \times 10^{16}$ & 4.5 & 9.982 & 0.75162 & 2.66 \\
\hline $3 \times 10^{16}$ & 2 & 12.2 & 0.75854 & 3.22 \\
\hline $6.88 \times 10^{16}$ & 4.5 & 4.6 & 0.30757 & 3.00 \\
\hline $8.5 \times 10^{16}$ & 1 & 23.2 & 0.62143 & 7.47 \\
\hline $9 \times 10^{16}$ & 1 & 11.23 & 0.42017 & 5.34 \\
\hline $1 \times 10^{17}$ & 2 & 5.12 & 0.26915 & 3.80 \\
\hline $1.3 \times 10^{17}$ & 1 & 8.1 & 0.29691 & 5.46 \\
\hline $1.48 \times 10^{17}$ & 1 & 7.2 & 0.26236 & 5.49 \\
\hline $1.5 \times 10^{17}$ & 2 & 8.2 & 0.27811 & 5.90 \\
\hline $2 \times 10^{17}$ & 1 & 2.67 & 0.13744 & 3.90 \\
\hline $2.45 \times 10^{17}$ & 1 & 2.5 & 0.12016 & 4.16 \\
\hline $2.5 \times 10^{17}$ & 1 & 2.3 & 0.1149 & 4.03 \\
\hline $3 \times 10^{17}$ & 2 & 3.5 & 0.12848 & 5.45 \\
\hline $3.64 \times 10^{17}$ & 1 & 5.0 & 0.13941 & 7.17 \\
\hline $6.65 \times 10^{17}$ & 1 & 2.4 & 0.07146 & 6.72 \\
\hline $1.5 \times 10^{18}$ & 1 & 2.8 & 0.05139 & 10.90 \\
\hline
\end{tabular}

by metal-organic vapor-phase epitaxy (MOVPE) in the concentration range of $6 \times 10^{15}-1.5 \times 10^{18} \mathrm{~cm}^{-3}$. The maximum electric field at breakdown was then derived from the breakdown voltage at different concentration and the maximum depletion layer width. These results are compared with the other workers for comparison.

\section{Estimation of breakdown voltage ( $\left.V_{\mathrm{BD}}\right)$}

The breakdown voltage for the case when the lowdoped base thickness $t$ is greater than the depletion region width $W$ is given by [17]

$V_{\mathrm{BD}}=\frac{\varepsilon_{\mathrm{o}} \varepsilon_{\mathrm{s}} E_{\mathrm{m}}^{2}}{2 q N_{\mathrm{D}}}$,

where $q$ is the electronic charge, $\varepsilon_{\mathrm{O}}$ is the permittivity of free space, $\varepsilon_{\mathrm{s}}$ is the permittivity of semiconductor. $N_{\mathrm{D}}$ is the background donor concentration, and $E_{\mathrm{m}}$ is the maximum electric field strength at breakdown at the specified background doping concentration.

If the base region is narrower than the depletion layer width, i.e. $t<W$ (a 'reach-through' diode [18]), the breakdown voltage is lowered because the depletion region reaches the highly doped contact layer. For such a reach-through (also called punch-through) case, the maximum electric field at which avalanche breakdown occurs is given by
$E_{\mathrm{m}}=\frac{V_{\mathrm{BD}}}{t}+\frac{q N_{\mathrm{D}} t}{2 \varepsilon_{\mathrm{o}} \varepsilon_{\mathrm{s}}}$.

The maximum depletion layer width at breakdown and the avalanche breakdown voltage can then be obtained from $\mathrm{E}_{\mathrm{m}}$

$W_{\mathrm{m}}=\frac{\varepsilon_{\mathrm{o}} \varepsilon_{\mathrm{s}}}{q N_{\mathrm{D}}} E_{\mathrm{m}}$

and

$V_{\mathrm{BD}}=\frac{1}{2} E_{\mathrm{m}} W_{\mathrm{m}}$

for abrupt junctions. The dependence of avalanche breakdown voltage $V_{\mathrm{BD}}$ for an abrupt junction on the drift region doping density $N_{\mathrm{B}}$ and energy gap $E_{\mathrm{g}}$ for $\mathrm{Ge}, \mathrm{Si}, \mathrm{GaAs}$ and $\mathrm{GaP}$ can be obtained from the well known Sze and Gibbons expression [19]

$V_{\mathrm{BD}}=60\left(\frac{E_{\mathrm{g}}}{1.1}\right)^{3 / 2} \times\left(\frac{N_{\mathrm{B}}}{10^{16}}\right)^{(-3 / 4)}$.

Using the expression, it is possible to determine the doping level of the drift region for each semiconductor to achieve any desired breakdown voltage.

\section{Experimental procedure}

The Schottky diodes were fabricated on epitaxial Sidoped n-type GaAs films grown on Si-doped 
$\left(\sim 2 \times 10^{18} \mathrm{~cm}^{-3}\right) \mathrm{n}^{+}$-GaAs substrates $(100) 2^{\circ}$ off towards [110] direction using the MOVPE technique and by thermal evaporating Au under vacuum. The epitaxial n-type GaAs layers of carrier concentration $6 \times 10^{15}-1.5 \times 10^{18} \mathrm{~cm}^{-3}$ were used for this study. The details of the growth procedure can be found elsewhere [20-23]. The carrier concentrations were determined using the reverse bias capacitance-voltage $(C-V)$ characteristics at $1 \mathrm{MHz}$ on a HP 4194A LCR bridge. The carrier concentrations were further confirmed by Bio-Rad electrochemical capacitance-voltage (ECV) polaron profiler. Room temperature current-voltage $(I-V)$ characteristics of the diodes were checked using automated arrangement consisting of a Keithley source measure unit SMU 236, an IBM PC 486, and a probe station. The breakdown voltage $V_{\mathrm{BD}}$ was measured at a reverse current density of $0.08 \mathrm{~A} \mathrm{~cm}^{-2}$.

\section{Results and discussion}

The results of the measurements are summarized in Table 1. Table 1 lists the measured carrier concentration and thickness of the epitaxial layer, measured breakdown voltage, the maximum electric field and the depletion layer width at breakdown voltage. In order to compare the experimental results with the theoretical analyses, the above parameters have been plotted as a function of the donor concentration in Fig. 1. From Fig. 1 it is seen that the breakdown voltage at low carrier concentration was far from the theoretical curves obtained by Sze and Gibbons [19]. Despite some scatter in the experimental data points arising from the low doping level material, reasonably good agreement was observed with the experimental data presented by Baliga et al. [13] using the vapor and liquid phase epitaxially grown materials. However, the breakdown voltages measured by Horvath et al. [11] either in planar or mesa diodes were far below from the theoretical curves. They pointed out that this may be due to very large defect densities greater than $1 \times 10^{6} \mathrm{~cm}^{-2}$ or may be due to the surface/interface effects or the edge effect influences the breakdown at low concentrations $[17,24]$. In the low carrier concentration (reach-through or punch-through case) the avalanche $V_{\mathrm{BD}}$ voltage is far from the theoretical predictions because the theoretical curves were calculated for the infinite current multiplication level [19]. The breakdown voltage at higher dopant concentrations, in our case, are in closer agreement with the theoretical predictions by Sze and Gibbons [19].

The breakdown voltages at different doping concentrations reported by several authors $[12,13,15,16]$ are in agreement; but some of their results are far from the theoretical curves predicted by Sze and Gibbons [19], Lee and Sze [25] and Okuto and Crowell [26], but are

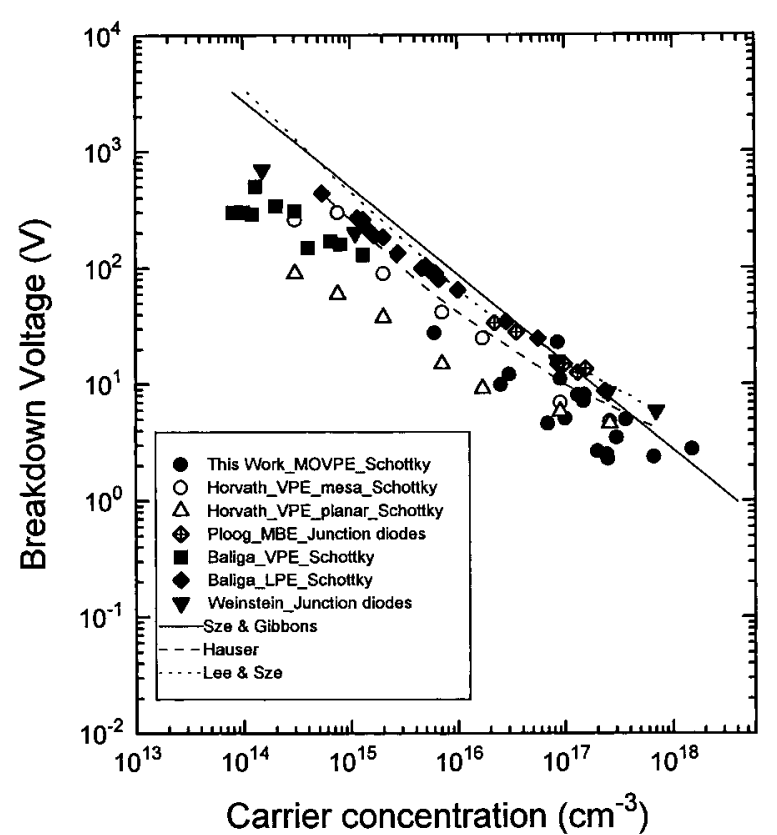

Fig. 1. Comparison of experimentally measured breakdown voltage of GaAs diodes with theoretical calculations published in the literature.

in closer agreement with Hauser's [27] calculations. As pointed out by Chynoweth et al. [28] and Moll [29] for junctions with breakdown at voltages less than $8 \mathrm{~V}$ for GaAs, the mechanism is mainly by tunneling, or direct field ionization of carriers. This breakdown voltage characteristics of Si-doped n-type GaAs is the extension of the $V_{\mathrm{BD}}$ at higher dopant concentrations. In this figure, the breakdown voltages obtained by other workers [11-13,15,16] in different growth techniques are also shown for comparison.

The maximum depletion layer width at breakdown calculated for the above epitaxial layers (both avalanche and Zener region) using Eqs. (1) and (3) is shown in Fig. 2. In Fig. 2, the theoretical curves published by Sze and Gibbons [19] and the experimental data published by other workers [11-13] in different growth techniques are also shown. From this figure it is seen that the depletion layer widths derived by several workers [12,13] are agreeing with each other except for the work done by Horvath et al. [11] in the vapor-phase (VPE) growth process of planar diodes. From Fig. 2 it can be concluded that a close agreement of the calculated maximum depletion layer width with the theoretical analysis of Sze and Gibbons [19] is established.

The maximum electric fields at breakdown voltages are also determined using the measured breakdown voltages and Eq. (1) for the diodes of different concentrations. These data are shown in Fig. 3 for compari- 


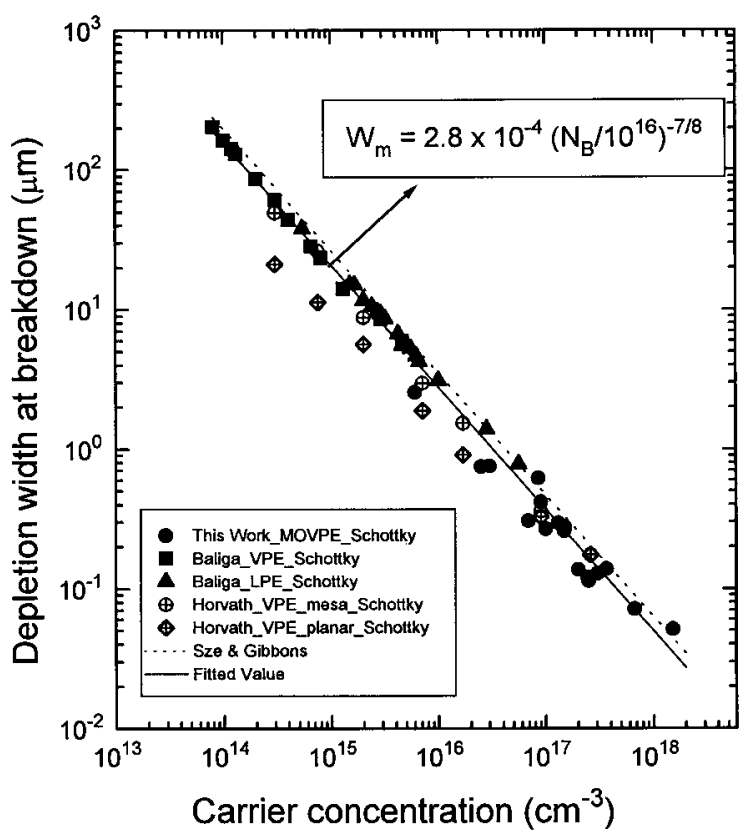

Fig. 2. Maximum depletion layer width at avalanche breakdown voltage of GaAs diodes as a function of carrier concentration.

son with the theoretical analysis of Sze and Gibbons [19]. The maximum electric field at breakdown increases with increasing carrier concentration because of a decrease in the avalanche path length [12]. It can also be seen from Fig. 3 that the maximum electric field is less compared to the theoretical predictions by Sze and Gibbons [19], although the depletion layer width is very close to the theoretical curves [19].

\section{Conclusions}

In conclusion, the breakdown characteristics of GaAs have been measured over carrier concentrations ranging from $6 \times 10^{15} \mathrm{~cm}^{-3}$ to $1.5 \times 10^{18} \mathrm{~cm}^{-3}$ using $\mathrm{Au}-$ Schottky barrier diodes formed on n-type GaAs layers grown by low pressure metal-organic vaporphase epitaxial technique. The measured breakdown voltage is in close agreement with the theoretical curves predicted by Sze and Gibbons [19] in the higher concentration but there is a deviation in the low carrier concentrations. The maximum depletion layer width was found to be in good agreement with the theoretical curves predicted by Sze and Gibbons [19], while the maximum electric field has been found to be less in the lower concentrations. The results of this study on the breakdown characteristics of GaAs are the extension of the $V_{\mathrm{BD}}$ characteristics measured by Baliga et al. [13] in the higher concentration range and it will be

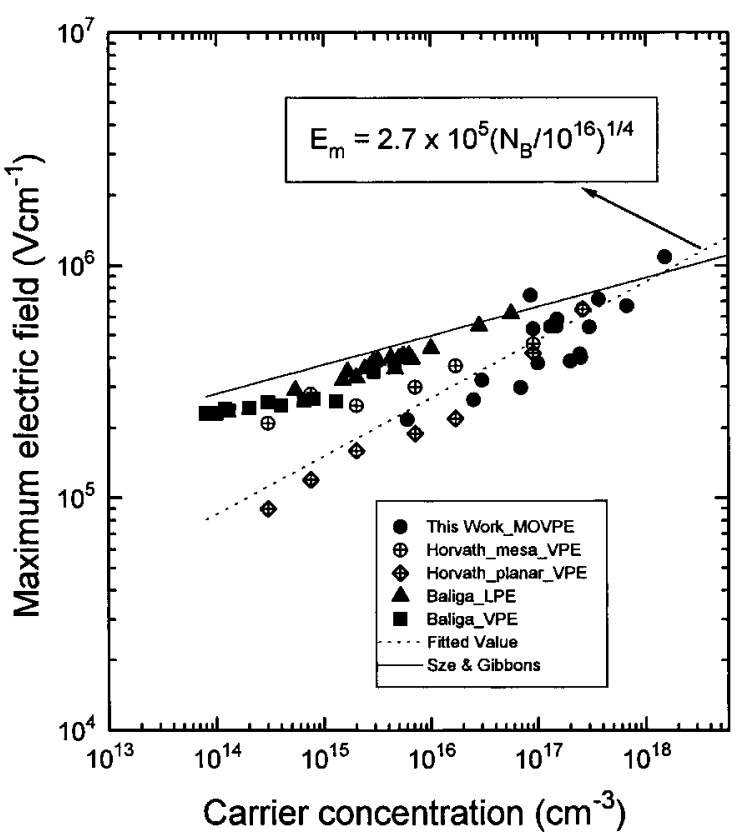

Fig. 3. Maximum electric field strength at avalanche breakdown voltage as a function of carrier concentrations in GaAs.

useful for the design and development of GaAs switching devices as well as the design of the emitter-base region of bipolar transistors.

\section{References}

[1] Baliga BJ, Sears AR, Barnicle MM, Campbell PM, Garwacki W, Walden JP. IEEE Trans Electron Devices 1985;32:1130.

[2] Pendharkar SP, Winterhalter CR, Shenai K. IEEE Trans Electron Devices 1995;42:1847.

[3] Ashkinazi G, Hadas T, Meyler B, Nathan M, Zolotarevski L, Zolotarevski O. Solid-State Electron 1993;36:13.

[4] Baliga BJ. Modern power devices. New York: John Wiley and Sons, 1987.

[5] Shenai K, Scott RS, Baliga BJ. IEEE Trans Electron Devices 1989;36:1811.

[6] Baliga BJ. J Appl Phys 1982;53:1759.

[7] Baliga BJ, Adler MS, Oliver DW. IEEE Electron Device Lett 1981;2:162.

[8] Spicer WE, Chye PW, Sheath PR, Su CY, Lindau I. J Vac Sci Technol 1979;16:1422.

[9] Baliga BJ, Ehle R, Sears A, Campbell P, Garwacki W, Katz W. IEEE Electron Device Lett 1982;3:177.

[10] Ashkinazi G, Hadas T, Meyler B, Nathan M, Zolotarevski L, Zolotarevski O. Solid-State Electron 1993;36:1793.

[11] Horvath ZJ, Tutto P, Nemeth-Sallay M, Stubnya G, Nemeth T, Gyuro I, Fineberg VI. Acta Phys Polonica A 1987;71:485. 
[12] Baliga BJ, Ehle R, Shealy JR, Garwacki W. IEEE Electron Device Lett 1981;2:302.

[13] Baliga BJ, Sears AR, Menditto P, Campbell PM. IEEE Electron Device Lett 1984;5:385.

[14] Sears, AR, Baliga, BJ, Barnicle, MM, Campbell, PM, Garwacki, W. IEDM Tech Dig 1983:229.

[15] Ploog K, Fischer A, Kunzel H. J Electrochem Soc 1981;128:400.

[16] Weinstein M, Mlavsky AI. Appl Phys Lett 1963;2:97.

[17] Sze SM. Physics of Semiconductor Devices, 2. New York: John Wiley and Sons, 1981.

[18] Bulucea C. Solid-State Electron 1991;34:1313.

[19] Sze SM, Gibbons G. Appl Phys Lett 1966;8:111.

[20] Hudait MK, Krupanidhi SB. Solid-State Commun 1998;108:457.
[21] Hudait MK, Krupanidhi SB. J Vac Sci Technol 1999;B17:1003.

[22] Hudait MK, Modak P, Hardikar S, Krupanidhi SB. Solid-State Commun 1997;103:411.

[23] Hudait MK, Modak P, Hardikar S, Rao KSRK, Krupanidhi SB. Mater Sci Eng B 1998;55:53.

[24] Solomon P, Klein N, Albert M. Thin Solid Films 1976;35:321.

[25] Lee MH, Sze SM. Solid-State Electron 1980;23:1007.

[26] Okuto Y, Crowell CR. Solid-State Electron 1975;18:161.

[27] Hauser JR. Appl Phys Lett 1978;33:351.

[28] Chynoweth AG, Feldman WL, Lee CA, Logan RA, Pearson GL, Aigrain P. Phys Rev 1960;118:425.

[29] Moll JL. Physics of Semiconductors. New York: McGraw-Hill, 1964. 